()

CORPUS PUBLISHERS

\section{Corpus}

International

Journal of

Oceanography

and Aquatic

Research (CIJOAR)

\section{Volume 1 Issue 1, 2021}

Article Information

Received date : October 19, 2021

Published date: October 25, 2021

\section{*Corresponding author}

Menny M Benjamin, Department of Drug Discovery \& Biomedical Sciences, Department of Regenerative Medicine \& Cell Biology, Medical University of South Carolina, USA; E-mail: benjamimmuscedu

\section{DOI: 10.54026/CIJOAR/1001}

\section{Keywords}

Marine Algae's; Petroleum Product; Ecosystem; Fossil Fuel; Greenhouse Gas

Distributed under Creative Commons CC-BY 4.0

\title{
Marine Algae's Major Role in Carbon Sequestration and Petroleum Product Independence
}

\author{
Menny M Benjamin ${ }^{1,2^{*}}$, George S Hanna ${ }^{1}$ and Mark T Hamann ${ }^{3}$ \\ ${ }^{1}$ Department of Drug Discovery \& Biomedical Sciences, Medical University of South Carolina, USA; E-mail: \\ benjamim@musc.edu \\ ${ }^{2}$ Department of Regenerative Medicine \& Cell Biology, Medical University of South Carolina, USA; E-mail: \\ hannag@musc.edu \\ ${ }^{3}$ Department of Public Health Sciences, Medical University of South Carolina, USA; E-mail: hamannm@musc. \\ $e d u$

\section{Opinion}

The equilibrium of the planet is a result biological, chemical, and physical forces working in concert to create interconnected and sustaining ecosystems. Organisms, both micro and macro, make tremendous contributions maintaining this balance. From chemical fixation to microbial decomposition, humans depend on intricate natural processes to not only survive in the world in which they live in, but to attempt to leave it in better condition for the next generation. The scientific consensus regarding necessary actions for limiting global warming to below the $20^{\circ} \mathrm{C}$ threshold has indicated that reducing Green House Gas (GHG) emissions alone will not be adequate. The halting of fossil fuel extraction and simultaneous removal of GHGs are considered necessary. This fact has drawn increased scrutiny to the global carbon cycle and the potential impact of Natural Climate Solutions (NCS), a suite of land stewardship practices that sequester carbon with the estimated potential to offset $21 \%$ of the current GHG emissions in the US while providing additional ecosystem services and commodities [1]. However, NCSs do not reduce the imperative need for mitigation in industrial sectors that produce economically essential commodities-fuels, materials and pharmaceuticals [2]. Generally, algae have largely been excluded from discussions regarding NCSs and engineered carbon sequestration despite being the dominant primary producers in most aquatic environments and a significant natural carbon sink through deep sea and coastal sediment formation [3]. Vegetative macroalgae (e.g. Sargassum) and unicellular phytoplankton, (e.g. coccolithophores) both demonstrate the capacity for massive scale blooms that are visible from space (Figure 1) and alter the biogeochemistry of their respective regions. For millennia these blooms served to regulate the global carbon cycle-contributing to what are now offshore petroleum reserves that currently support our energy economy. Algae and other marine autotrophs, a remarkably diverse suite of organisms, have been utilized by humans for consumption and industrial products for centuries and more recently to produce biofuels, pharmaceuticals, and even cosmetics. Such industries can provide the dual benefit of serving as a carbon sink, while also supporting the production of valuable and renewable commodities in a petroleum free economy.

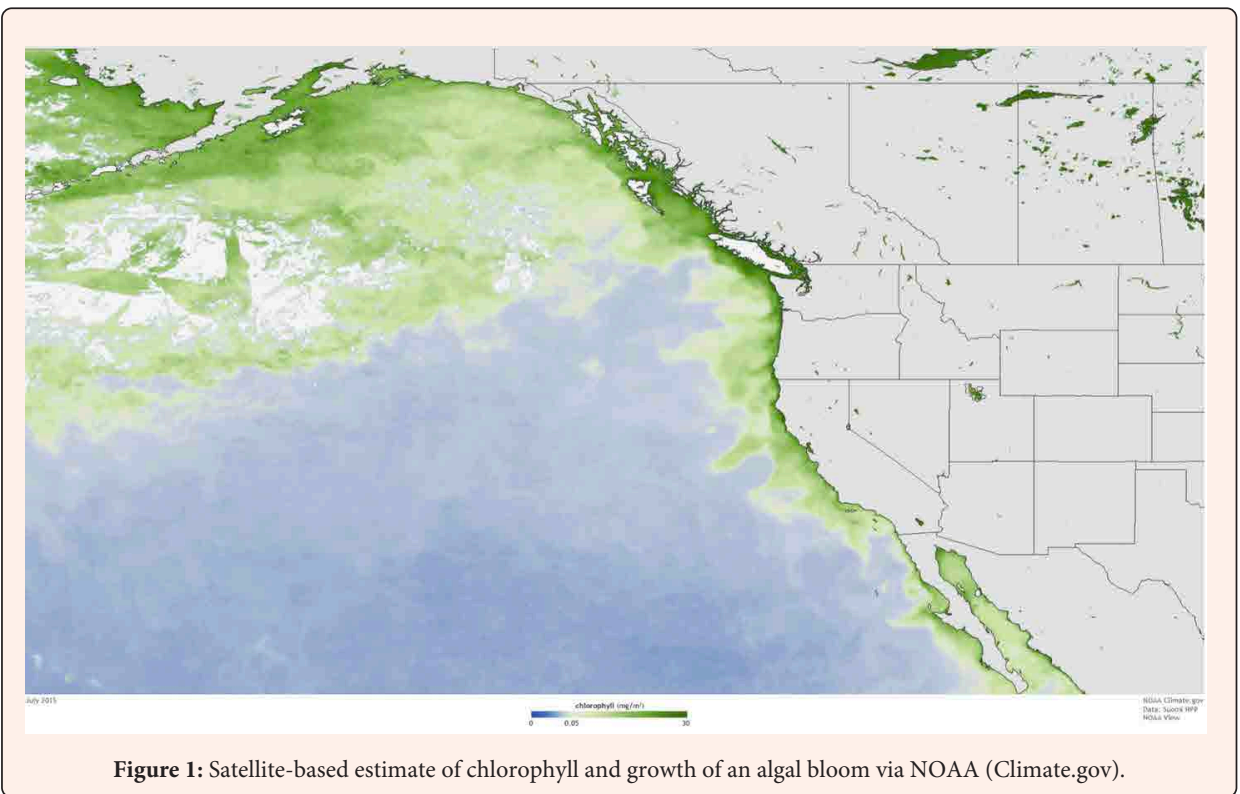

Climate change is an accelerating outcome of deleterious human activity on the environment due to the combustion of reduced carbon reserves. Industries utilizing petroleum to produce carbon-producing fossil fuels, for example, significantly contribute to the excess $\mathrm{CO}_{2}$ released into the atmosphere and absorbed by our oceans. The oceans have absorbed over $30 \%$ of anthropogenic $\mathrm{CO}_{2}$ emissions since the industrial revolution, and regional differences in carbon storage rates are due to climate-driven changes [4]. As a result, existential threats, like rising global temperatures and ocean acidification, are disrupting the natural balance of carbon at unprecedented rates. Solutions are urgent to mitigate the factors responsible for climate change in an environmentally sustainable and economically viable fashion. Microalgae and macroalgae, which serve as major marine carbon sinks that sequester much of the organic compounds in coastal and benthic sediments, can be utilized innovatively to fight climate change. In fact, harmful algal blooms have adapted to factors, such as eutrophication, via being capable of 
sequestering an influx of nutrients from terrestrial runoff and gasses from the atmosphere. Although these harmful blooms are responsible for producing toxic metabolites, like kainic acid [5], which is linked to the Alzheimer's neurodegenerative disease, they are excellent sequesters of Blue Carbon. The term 'Blue Carbon' refers to organic carbon that is captured, stored, and sequestered by the oceans and coastal ecosystems [6]. Algae and other marine primary producers fix over $50 \%$ of the planet's carbon via photosynthetically driven $\mathrm{CO}_{2}$ assimilation. They greatly contribute to the annual biological sequestration of global $\mathrm{CO}_{2}$, since they photosynthesize at high rates with a Gross Primary Production (GPP) of $\geq 3,000 \mathrm{GC} \mathrm{m}^{-2}$ year $^{-1}$ [7]. Algae-based industries that take advantage of marine algal blooms as natural and efficient sequesters of carbon can set the stage for alternatives to petroleum products.

Crop-based biofuel production is now a century-old process and has paved the way for additional feedstocks and processing techniques to be considered for expanding the chemical space obtainable through fossil-fuel independent production [8]. A key consideration for the viability of NCS-based biotechnologies is their competition with productive land necessary for food-crops. This is where algae-based technologies have distinct advantage. They can sequester carbon, mitigate nutrient runoff, provide positive ecosystem services, diversify agriculture, and serve as the feedstock for industries without displacing current agricultural operations. Existing methodologies of utilizing algal biomass can be divided into passive and active techniques. Passive refers to the harvesting of naturally occurring blooms through the filtration of microalgae from a body of wate or physical collection of existing macroalgae-often after it has drifted ashore. Active techniques largely refer to the aquaculture production of algal biomass. These systems can be in the environment-as is the case with many edible macroalgae species-or in bioreactors that range from closed systems with selective inputs to industrial systems that can be incorporated into wastewater treatment facilities [9-10]. In the United States, over a quarter of global petroleum and other carbon-producing fossil fuels are consumed as energy or as feedstock for industrial products. Transportation and health care, among other sectors of daily life, are majorly dependent on petroleum-derived products, such as gasoline to power a combustible engine and petrochemicals to produce plastic medica supplies and drugs. It is estimated that over 3.4 billion pounds of petroleum-derived plastics were used in health care in 2010, and that petrochemicals were responsible for manufacturing $99 \%$ of pharmaceuticals and reagents used to promote human health [11]

This dependency may be convenient for humans but is not sustainable for the environment, as excess $\mathrm{CO}_{2}$ released into the atmospheres and absorbed by our oceans are driving climate change. Greater efforts must be set in motion that strive to mitigate anthropogenic carbon emissions and other pollutions from industries that manufacture non-renewable energy and petroleum-derived products. Potential solutions to tackle the climate crisis are utilizing algae in renewable and efficient technologies/methodologies. For example, nutrient extraction from wastewaters, biofuel production, and replacing petrochemicals as feedstocks used in industrial production. Renewable energy to replace fossil fuels, as well as developing green bio-friendly feedstocks for industry production, is possible by focusing on sustainable strategies that limit the output of excess organic compounds and nutrients. Algae's ability to sequester carbon, as well as inorganic nitrogen, phosphorus, and iron, could been used to treat aquacultural wastewaters via Moving Bed Bio Reactors (MBBRs). These bioreactors cultivate macroalgae biomass, decrease Proteobacteria, but increase Bacteroidetes to induce a synergistic effect to improve the efficiency of algal sequestration [12]. These bioreactors could be used to reduce eutrophication produced from aquaculture and other industries, which is responsible for the production of harmful metabolites linked to detrimental health risks and biodiversity loss [13].

Renewable energy is more than just solar panels and wind turbines. Biofuels, which are energy sources derived from organic biomass, have reduced carbon emissions by at least 590 million tons, as of 2015. Microalgae and cyanobacteria are considered producers of 'third-generation' biofuels due to their ability to photosynthesize in a more direct and energy effect manner compared to generic plants. For example, bioethanol production via algal fermentation is approximately 9,000 L/hectare/year, whereas corn only produces $600 \mathrm{~L} /$ hectare/year.8 Biofuels produced from algae, most notably bioethanol, can be chemically converted to sustainable and renewable plastics, unlike petrochemical products heavily used in healthcare: medical equipment, pharmaceuticals, and cosmetics. One strategy is utilizing fixed-bed catalytic reactors to dehydrate bioethanol from algae to form ethylene. Using bioethanol instead of fossil fuels to produce ethylene for polyethylene synthesis would be a major contributor for reducing carbon emissions from petrochemical production [14]. An additional method to naturally reduce carbon emissions is the mass production of algae-derived biofuels via the artificial induction of algal blooms. Replacing petroleum-derived feedstocks used in transportation and other industries is possible by the addition of fertilizers, like iron, to increase biomass and overall carbon sequestration [15], and by stimulating solar-to-product conversion efficiency via engineering strategies that target the bioconversion of photon energy into fixed carbon [8]

Algae contain renewable and sustainable natural compounds that can be utilized for an array of consumer products, ranging from the food industry to health care. For example, phycocolloids used in agar production are primarily found in red algae (Rhodophyta) and are used commercially as gelling agents and as stabilizers for preservation. 'Cosmeceuticals', which lie between the cosmetic and pharmaceutical fields, use algal-derived compounds as either drug vehicles or as active compounds for therapeutic ingredients: palmitic acid and other fatty acids as vehicles used in cosmetics as emulsifiers, whereas polysaccharides, like carrageenan and alginate, used as waterbinding agents that balance moisture [16]. In addition, algae-derived substances can be utilized for the formation of biopolymers to form algae-based bioplastics that are renewable and biodegradable. For example, algae oil has been used to develop biopolyols to produce polyurethane foam (PUF), which could be used as renewable and raw materials for new technologies, such as three-dimensional (3D) printing [17]. Only a handful of companies have pushed for green environmentally friendly products, mainly due to profits, yet there is a rising trend and a consumer demand for commodities that are healthier for the planet. For instance, Adidas has replaced some of the soles of its popular Yeezy shoes with algae foam grown from their own hydroponic farms. As time progresses, there will an increase in stringent environmental regulations and policies that will monitor industry and push companies towards renewable and sustainable alternatives to everyday products. Perhaps algae-based technologies and strategies can pave the way for natural mitigation of greenhouse gasses and petroleum independence.

While these harmful algal blooms are a major cause for concern to both human and environmental health, they also demonstrate the immense capacity and potential of algae to convert atmospheric carbon and nutrient waste into a vast array of chemicals at exceedingly large scales. The hope is that if managed properly, algae-based technologies can reduce human's impact on climate change and pollution-driven environmental degradation while simultaneously producing valuable commodities that currently require fossil fuels to produce. Afterall, fossil fuels are nothing more than ancient autotrophs locked away in the Earth's crust-extracting them makes little sense when considering the current excess of $\mathrm{CO}_{2}$ in the atmosphere and a ready supply of solar-powered chemical reactors (algae) eager to grow.

\section{References}

1. Fargione JE, Steven B, Boucher T, Scott D, Conant R, et al. (2018) Natural climate solutions for the United States. Science 4(11).

2. Anderson CM, Ruth SD, Robert L, Pamela AM, Daniel CN, et al. (2019) Natural climate solutions are not enough. Science 363(6430):933-934.

3. KrauseJ, Duarte CM (2016) Substantial role of macroalgae in marine carbon sequestration. Nature Geoscience 9: 737-742.

4. Gruber DC, Carter BR, Feely RA (2019) The oceanic sink for anthropogenic $\mathrm{CO}_{2}$ from 1994 to 2007. Science 363(6432):1193-1199.

5. Holdt SL, Kraan S (2011) Bioactive compounds in seaweed: functional food applications and legislation. Journal of Applied Phycology 23(3): 543-597.

6. Macreadie PI, Anton A (2019) The future of Blue Carbon science. Nat Commun 10(1): 3998 .

7. Chung IK, Beardall J, Mehta S, Sahoo D, Stojkovic S (2010) Using marine macroalgae for carbon sequestration: a critical appraisal. Journal of Applied Phycology 23(5): 877-886.

8. Liu Y, Cruz MP, Zargar A, Belcher MS, Pang B, et al. (2021) Biofuels for a sustainable future. Cell 184(6): 1636-1647.

9. Carlos MD, Annette B, Dorte KJ (2021) A seaweed aquaculture imperative to meet global sustainability targets. Nature Sustainability.

10. Fabris M, Abbriano RM, Pernice M, Sutherland DL, Commault AS, et al. (2020) Emerging Technologies in Algal Biotechnology: Toward the Establishment of a Sustainable, Algae-Based Bioeconomy. Front Plant Sci 11: 279.

11. Hess J, Bednarz D, Bae J, Pierce J (2011) Petroleum and Health Care: Evaluating and Managing Health Care's Vulnerability to Petroleum Supply Shifts. American Journal of Public Health 101(9): 1568-1579.

12. Li X, Deng Y, Li X, Ma X, Wang J, et al. (2020) Integration of Marine Macroalgae (Chaetomorpha maxima) with a Moving Bed Bioreactor for Nutrient Removal from Maricultural Wastewater. Archaea 2020: 8848120.

13. Suddick EC, Whitney P, Townsend AR, Davidson EA (2012) The role of nitrogen 
in climate change and the impacts of nitrogen-climate interactions in the United States: foreword to thematic issue. Biogeochemistry 114 (1-3): 1-10.

14. Cameron G, Linda L, Levine J, Nagulapalli N (2012) Process Design for the Production of Ethylene from Ethanol. Penn Engineering.

15. Smetacek V, Klaas C, Strass VH (2012) Deep carbon export from a Southern Ocean iron-fertilized diatom bloom. Nature 487(7407), 313-319.
16. Leandro A, Pereira L, Goncalves AMM (2019) Diverse Applications of Marine Macroalgae. Mar Drugs 18(1): 17.

17. Chia WY, Ying DY, Khoo KS, Kay AN, Chew KW (2020) Nature’s fight against plastic pollution: Algae for plastic biodegradation and bioplastics production. Environmental Science and Ecotechnology 4: 100065 